\title{
CONDROMA DE LARINGE: APRESENTAÇÃO ATÍPICA
}

\section{LARYNGEAL CHONDROMA: AN ATYPICAL PRESENTATION}

\section{Leonardo C. B. de Sá ${ }^{\text {; José R C Fernandes }}$; Roberto Campos Meirelles - TCBC-RJ ${ }^{3}$}

\section{INTRODUÇÃO}

Entre os tumores benignos da laringe, encontra-se o papiloma, o mais comum, seguido de outros menos usuais como condroma, neurofibroma, leiomioma, angiofibroma, mioblastoma, mioma e hemangioma, em ordem decrescente de freqüência ${ }^{1,2}$. Os tumores cartilaginosos da laringe são raros, com cerca de 250 casos descritos, representando menos de $1 \%$ dos tumores laríngeos. ${ }^{1,3}$.

Os autores descrevem um caso de condroma de laringe com apresentação atípica, tratado no Serviço de Otorrinolaringologia do Hospital Universitário Pedro Ernesto.

\section{RELATO DO CASO}

Paciente, 41 anos, masculino, tabagista, foi internado com dispnéia progressiva de média intensidade, de início há um ano. Relatou acidente automobilístico há 20 anos, com parada cardiorespiratória e estado de coma. Ficou traqueostomizado por 32 dias. Desde essa época surgiu disfonia discreta e permanente. A laringoscopia indireta evidenciou tumoração lisa, hiperemiada, abaulando a aritenóide esquerda, com extensão supraglótica e redução discreta da luz laríngea. A tomografia computadorizada revelou massa de densidade de partes moles e de cartilagem, obliterando a luz laríngea (Figura 1). Internado para biópsia sob anestesia geral, seu quadro agravou com aumento da dispnéia, sendo realizada traqueostomia sob anestesia local.

Dois dias após, foi submetido a microlaringoscopia direta para biópsia, que foi difícil pela consistência extremamente endurecida da tumoração. O resultado histopatológico revelou processo inflamatório crônico inespecífico. Decidiuse pela laringofissura, com abertura da cartilagem tireóide para remoção da lesão cartilaginosa. Encontrada lesão extremamente endurecida, aderente, sem plano de clivagem com a cartilagem normal, de coloração habitual, estendendo-se inferiormente até a metade direita cricóide (Figura 2).

A massa encapsulada foi totalmente retirada por enucleação, acompanhada de raspado do tecido livre adjacente com conservação do arcabouço cricóide e de seu pericôndrio. $\mathrm{O}$ exame histopatológico revelou condroma.

Foi descanulizado no oitavo dia pós-operatório e encontra-se assintomático, há um ano, em acompanhamento pelo Serviço.

\section{DISCUSSÃO}

O condroma tem crescimento lento, acometendo freqüentemente a cartilagem cricóide $(70 \%)^{4}$, seguida pela tireóide, aritenóide e epiglote, podendo interferir, algumas vezes, com a mobilidade aritenoidea ${ }^{1,2}$. Acomete mais

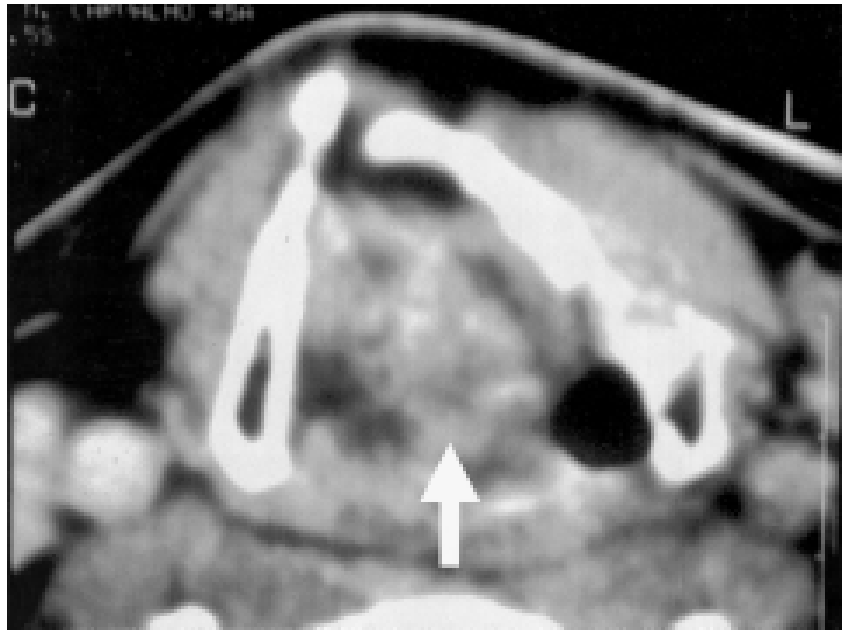

Figura 1 - Lesão tumoral obstruindo a luz laríngea (seta). Assimetria das porções laterais da cartilagem tiróide.

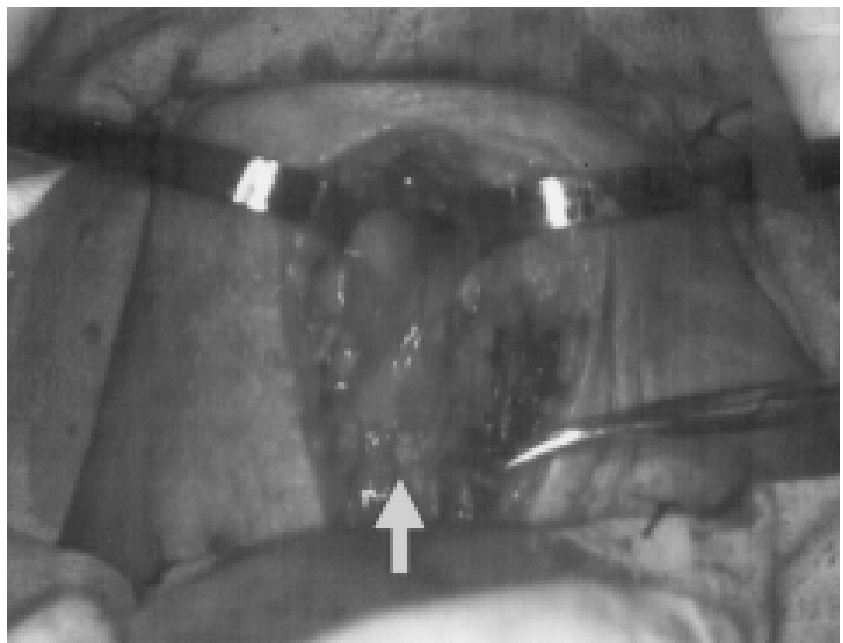

Figura 2 - Após laringofissura - lesão tumoral dura, sem planos definidos.

1. Médico do Serviço de Otorrinolaringologia do Hospital Universitário Pedro Ernesto; Universidade do Estado do Rio de Janeiro.

2. Professor Auxiliar da Disciplina de Otorrinolaringologia da Faculdade de Ciências Médicas da Universidade do Estado do Rio de Janeiro.

3. Chefe do Serviço de Otorrinolaringologia do Hospital Universitário Pedro Ernesto e Professor Adjunto da Faculdade de Ciências Médicas da Universidade do Estado do Rio de Janeiro. 
comumente adultos masculinos após $40 \operatorname{anos}^{3}$. Normalmente se apresenta por disfonia e, mais raramente, dispnéia lentamente progressiva. A disfagia ocorre quando há comprometimento da articulação cricoaritenoidea.

O aspecto é semelhante aos demais tumores laríngeos, apresentando mucosa intacta, com ou sem hiperemia, com massa subjacente dura ${ }^{4}$. No caso relatado havia franca assimetria laríngea com estreitamento da luz por tumoração glótica e supraglótica de origem aritenóidea, aspecto pouco específico. Na tomografia computadorizada o achado mais comum é o de massa arredondada e encapsulada ou imagem em ponta de flauta, não invasiva, com ou sem calcificação ${ }^{5}$.

A biópsia endoscópica com pinças delicadas não é conclusiva porque obtém-se apenas mucosa, conforme ocorrido também em nosso procedimento inicial ${ }^{1,2}$.

Por causa do crescimento lento e da hipocelularidade, pode ser difícil a diferenciação entre condromas e condrossarcomas de baixo grau de malignidade. Observa-se estrutura heterogênea, constituída de lóbulos de cartilagem hialina e baixa celularidade ${ }^{3}$. A matriz cartilaginosa da estrutura hialina é abundante e não se observam atipias celulares ${ }^{3}$.

O tratamento de escolha é a cirurgia conservadora para remoção completa do tumor com margens de segurança livres ${ }^{1,2,4}$, procedimento adotado por nosso Serviço. A laringectomia está indicada quando há comprometimento de mais de metade da cartilagem cricóide com desvio importante da linha média, dificuldade de exérese conservadora e na recidiva tumoral ${ }^{4}$.

Em caso de recidiva deve-se afastar condrossarcoma, porque as recidivas de condromas são raras depois da ressecção completa ${ }^{3,4,5}$. Há casos de transformação sarcomatosa e aparecimento de condrossarcoma anos após a remoção de um condroma, evidenciando a necessidade de acompanhamento pós-operatório a longo prazo ${ }^{2,3}$.

\begin{abstract}
The authors report a case of laryngeal chondroma, a rare benign larynx tumor in the cricoid and arytenoid cartilages. There are aproximately 250 cases previously described in literature. A male, 41 year-old patient, presented a severe and progressive dyspnea leading to tracheostomy. Direct microlaryngoscopy revealed arytenoid enlargement and subglottic stenosis and the endoscopical biopsy was inconclusive, since the tumor present a hard gnistency. We performed surgical excision by laringofissura and total resection of the tumor, with good result. The histopathological examination showed a chondroma with no malignance (Rev. Col. Bras. Cir. 2006; 33(2): 126-127).
\end{abstract}

Key words: Laryngeal neoplasms; Chondroma; Arytenoid cartilage.

\section{REFERÊNCIAS}

1. Raji A, Mahtar M, Atlassi B, et al. Les tumeurs bénignes rares du larynx: á propos de 17 cas. Rev Laryngol Otol Rhinol (Bord). 2001;122(4):245-8.

2. Thome R, Thome DC, de la Cortina RA. Long-term follow-up of cartilaginous tumors of the larynx. Otolaryngol Head Neck Surg. 2001;124(6):634-40.

3. Lewis JE, Olsen KD, Inwards CY. Cartilaginous tumors of the larynx: clinicopathologic review of 47 cases. Ann Otol Rhinol Laryngol. 1997;106(2):94-100.

4. Saydam L, Koybasi S, Kutluay L. Laryngeal chondroma presenting as an external neck mass. Eur Arch Otorhinolaryngol. 2003;260(5):239-41.
5. Wang SJ, Borges A, Lufkin RB, et al. Chondroid tumors of the larynx: computed tomography findings. Am J Otolaryngol. 1999;20(6):379-82

Como citar este artigo:

Sá LCB, Fernandes JRC, Meirelles RC. Condroma de laringe: apresentação atípica. Rev Col Bras Cir. [serial on the internet] 2006 MarApr;33(2). Available from URL: http://www.scielo.br/rcbc

Endereço para correspondência:

Dr. Leonardo Sá

Rua General Glicério 335/ 804 - Laranjeiras

22245-120- Rio de Janeiro- RJ

Tel: (0xx21)265-3044

E-mail: leocsa@aol.com 